\title{
ANALISA KEKUATAN PENGELASAN DAN PAKU PADA RANGKA MESIN PEMBANGKIT LISTRIK TENAGA UAP 1300 WATT
}

\author{
SUMARNO \\ Program Studi Teknik Mesin, Fakultas Teknik, Universitas Muhammadiyah Tangerang \\ Jl. Perintis Kemerdekaan I/33 Cikokol-Tangerang \\ E-mail: bagosumarno76@gmail.com
}

\begin{abstract}
Abstrak
Dengan semakin meningkatnya penggunaan energi yang dibutuhkan dari sumber-sumber yang diakibatkan oleh fosil purba, semakin terancam punah dan menipisnya cadangan energi fosil di dunia merupakan fakta yang harus diterima bahwa penggunaan energi berbasis fosil telah menjadi salah satu penyebab kelangkaan energi. , maka untuk itu perlu dilakukan pengembangan dan pemanfaatan energi terbarukan yang dimiliki. Energi terbarukan dibutuhkan untuk mendukung kebutuhan listrik yang terus meningkat. Indonesia mengoptimalkan pengembangan sumber energi alternatif guna mengurangi ketergantungan pada sumber energi tak terbarukan (fosil). Pemanfaatan energi pada tahun 2019 masih relatif kecil dibandingkan dengan sumber energi berbasis fosil. Dari hasil penelitian yang telah dilakukan, didapatkan rencana pengelasan pada rangka pembangkit listrik tenaga uap dinyatakan aman karena tegangan tarik yang diijinkan adalah $7.027 \mathrm{~kg} / \mathrm{mm} 2<7.9 \mathrm{~kg} / \mathrm{mm} 2$, untuk perencanaan paku keling tunggal adalah dikatakan aman karena efisiensi maksimum $26 \%$ dari desain adalah $21 \%<26 \%$.
\end{abstract}

Kata kunci: pengelasan, paku keling, pembangkit listrik tenaga uap gas

\section{Pendahuluan}

Dengan semakin banyaknya pemakaian energy yang dibutuhkan dari sumber yang ditimbulkan oleh fosil-fosil purba, maka semakin hampir punah dan menipisnya cadangan energi fosil di dunia merupakan kenyataan yang harus diterima bahwa pemakaian energi berbahan dasar dari fosil telah menjadi salah satu penyebab terjadinya kelangkaan energi, maka untuk itu perlu melakukan pengembangan dan pemanfaatan energi terbarukan yang dimiliki. Pengembangan energi terbarukan di Indonesia untuk menggantikan energi konvensional ditandai dengan banyak pengembangan energi alternatif untuk menggantikan energi konvensional, seperti: pembangunan PLTU, PLTS, dan PLTA yang menggantikan pembangkit listrik berasal dari bahan bakar minyak dan batu bara.

Energy terbarukan dibutuhkan untuk menunjang kebutuhan energy listrik yang semakin hari semakin meningkat. Indonesia mengoptimalkan pengembangan sumber energi alternatif supaya mengurangi ketergantungan terhadap sumber energi yang tidak dapat diperbaharui (fosil). Pemanfaatan energi pada tahun 2019 ini masih relatif kecil dibandingkan dengan sumber-sumber energi berbasis fosil.
Indonesia memiliki Potensi Energi Baru Terbarukan (EBT) yang cukup besar diantaranya, mini/micro hydro sebesar $450 \mathrm{MW}$, Biomass $50 \mathrm{GW}$, energi surya 4,80 $\mathrm{kWh} / \mathrm{m} 2 /$ hari, energi angin 3-6 m/det dan energi nuklir $3 \mathrm{GW}$. Upaya untuk bisa mengembangkan energi air mencakup pengembangan energi air untuk listrik dan non listrik (pemompaan air untuk irigasi dan air bersih), pengembangkan teknologi energi air yang sederhana untuk skala kecil $(10 \mathrm{~kW})$ dan skala menengah (50 - $100 \mathrm{~kW})$ dan mendorong pabrikan memproduksi skala kecil dan menengah secara massal.

Berdasarkan penjelasan diatas, maka penulis tertarik untuk meneliti pembangkit listrik dengan menggunakan piston. Dimana piston ini nantinya akan menjadi tenaga gerak untuk memutar generator listrik. Pada pembangkit listrik tersebut diperlukan pula kerangka untuk menjadikan pembangkit listrik tenaga uap air tersebut menjadi lebih kuat. Oleh sebab itu penulis mengambil judul Tugas Akhir yaitu "ANALISA KEKUATAN PENGELASAN DAN PAKU KELING PADA 


\section{RANGKA MESIN PEMBANGKIT LISTRIK} TENAGA GAS UAP 1300 WATT"

\section{Metode Penelitian}

\subsection{Proses Pembuatan Rangka Body}

Pemotongan material besi holo sesuai dengan ukuran yang telah ditentukan sebanyak yang dibutuhkan pada rangka mesin yaitu dengan sumbu horizontal sebanyak 8 buah, serta sumbu vertikal tiang sebanyak 4 buah, menggunakan gerinda duduk serta mistar baja, kemudian ujung besi holo yang sudah dipotong dihaluskan menggunakan gerinda tangan.

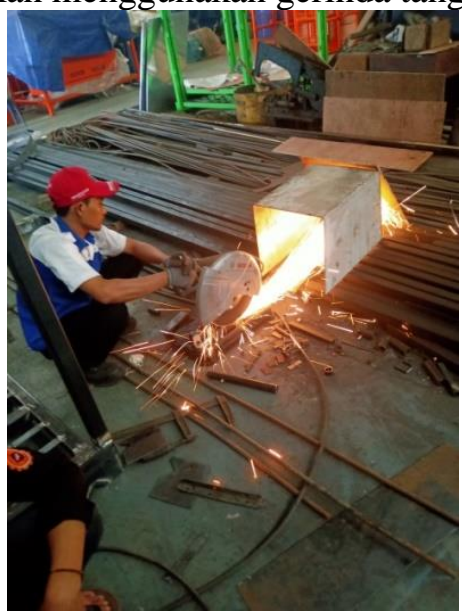

Gambar 1. Pemotongan Besi Holo

Menyambungkan material besi holo yang telah dipotong - potong dengan menggunakan mesin las listrik. Setelah menyambung material besi holo dengan mesin las listrik, kemudian memasang lembaran plat besi pada besi holo yang sudah di las sebelumnya dengan cara penyambungan menggunakan las listrik sebagai dudukan mesin serta penutup

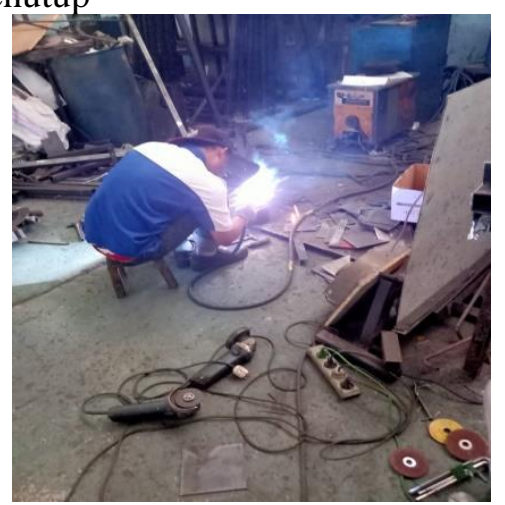

Gambar 2. Pengelasan Besi Holo
Membuat lubang pada besi holo menggunakan bor tangan yang berfungsi untuk lubang rivet. Kemudian pemasangan plat besi pada bodi mesin Pembangkit Listrik Tenaga Gas Uap menggunakan rivet yang dibantu pemasangannya menggunakan tang rivet.

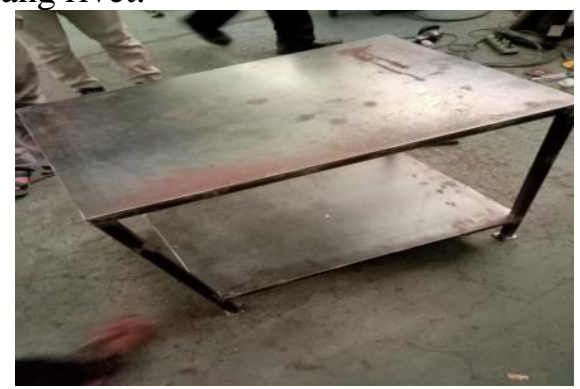

Gambar 3. Pengelasan Plat Besi

Lalu tahap selanjutnya adalah Melakukan pengecatan, mengecat tahap demi tahap dari cat dasar warna abu abu hingga setelah kering menggunakan warna orange.

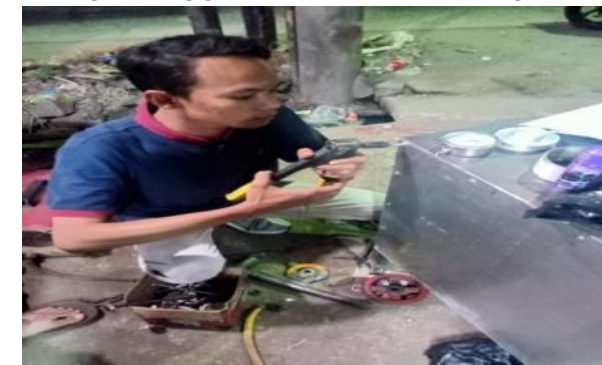

Gambar 4. Pemasangan Plat dengan Rivet

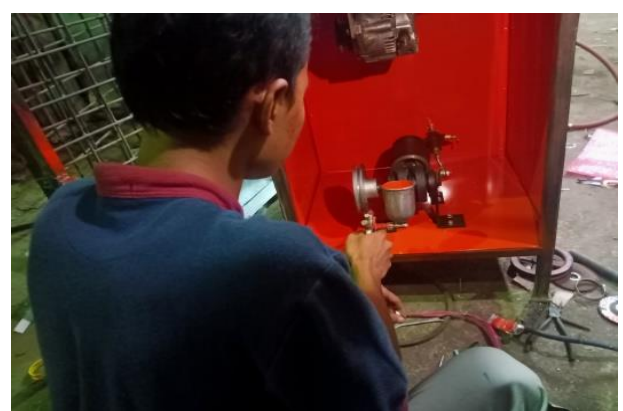

Gambar 5. Pengecatan Bodi Mesin

\section{Hasil dan Pembahasan}

\subsection{Analisa Lasan Pada Bodi Rangka}

Panjang Dan Lebar Pengelasan untuk rangka penunjang bodi dari pembangkit listrik ini adalah direncanakan dari bahan baja profil Holo ukuran $20 \mathrm{~mm}$ x $20 \mathrm{~mm}$. 


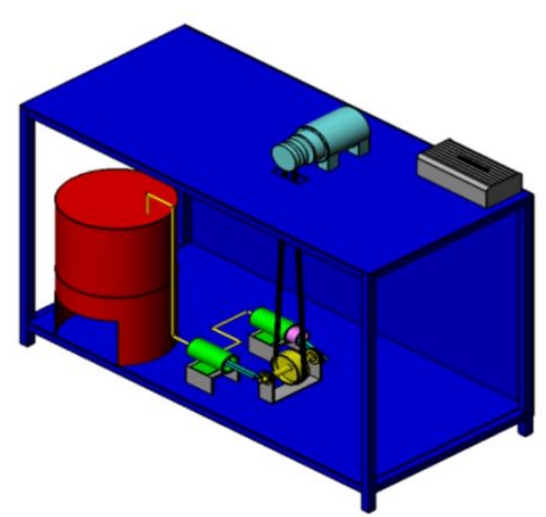

Gambar 6. Mesin PLTGU

Ukuran tinggi dudukan dari lantai sebesar 120 $\mathrm{mm}$ berbentuk persegi panjang, dengan ketebalan profil Holo adalah $2 \mathrm{~mm}$.

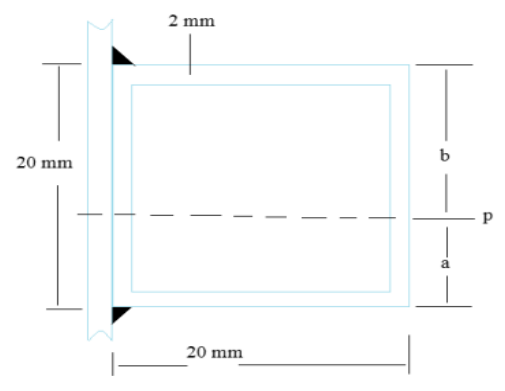

Gambar 7. Ukuran Holo

Besarnya beban yang di sanggah oleh rangka adalah sebesar $75 \mathrm{~kg}$. Ini setelah dilakukan pengukuran berat dari bagian-bagian dari pembangkit listrik tenaga piston. Pengelasan dilakukan setebal $5 \mathrm{~mm}$, untuk Tegangan geser yang diizinkan untuk pembebanan statis dapat diambil sebagai $75 \mathrm{Mpa}$. Analisa yang dilakukan adalah sebagai berikut :

$z b=\frac{(p h \times x \times l h)+(p h \times x \times s)}{(p h \times x)+(l h \times s)}$

(Sumber, Khurmi, Ghupta)

dengan :

$b$ : panjang holo dari atas ke titik temu a.

ph : panjang holo.

$x$ : tebal holo.

lh : lebar holo.

s : tebal lasan.

Contoh penggunaan persamaan di atas, misalkan diketahui

$$
b=\frac{(20 \times 2 \times 20)+(20 \times 2 \times 5)}{(20 \times 5)+(20 \times 2)} 7,1 \mathrm{~mm}
$$

maka

$$
\begin{aligned}
& a+b=20 \mathrm{~mm} \\
& \quad a=20 \mathrm{~mm}-7,1 \mathrm{~mm}=12,9 \mathrm{~mm}
\end{aligned}
$$

Sehingga,

$$
P=2 \times 0,707 \times x \times l \times \tau
$$

Diperoleh

$$
l=\frac{P}{0,707 \times x \times \tau}
$$

(Khurmi Gupta)

dimana :

$P=75 \mathrm{~kg} \times 9,81 \mathrm{~m} / \mathrm{s}^{2}=735,75 \mathrm{~N}$

$x=5 \mathrm{~mm}$

$\tau=75 \mathrm{Mpa}=75 \mathrm{~N} / \mathrm{mm}^{2}$

Maka,

$$
\begin{aligned}
& l=\frac{P}{0,707 \times x \times \tau} \\
& =\frac{735,75 \mathrm{~N}}{0,707 \times 5 \mathrm{~mm} \times 75 \mathrm{~N} / \mathrm{mm}^{2}}=2,78 \mathrm{~mm}
\end{aligned}
$$

Panjang lasan yang dilakukan adalah :

$$
\begin{gathered}
l_{a=} \frac{l \times b}{a+b}=\frac{2,78 \mathrm{~mm} \times 7,14 \mathrm{~mm}}{20 \mathrm{~mm}}=0,99 \mathrm{~mm} \\
l_{b}=l-l_{a}=2,78 \mathrm{~mm}-0,99 \mathrm{~mm}=1,79
\end{gathered}
$$

\subsection{Analisa Keamanan Las}

Tegangan tarik pengelasan dapat dicari dengan cara

$$
\sigma_{t}=\frac{2,83 \times T}{\pi s \times l^{2}}
$$

dengan $T$ adalah torsi dari piston sebesar $4820,88 \mathrm{~kg} / \mathrm{mm}$. $s$ tebal pengelasan $5 \mathrm{~mm}$. $\mathrm{l}$ panjang empat sisi dengan perhitungan

$$
l=(0,99+1,79) \times 4 s i s i=11,12 \mathrm{~cm}
$$

Maka :

$$
\begin{aligned}
\sigma_{t}=\frac{2,83 \times T}{\pi s \times l^{2}}= & \frac{2,83 \times 4820,88 \mathrm{~kg} \mathrm{~mm}}{\pi \times 5 \mathrm{~mm}(11,12)^{2} \mathrm{~mm}^{2}} \\
& =7,027 \mathrm{~kg} / \mathrm{mm}^{2}
\end{aligned}
$$

Sementara tegangan tarik yang diizinkan untuk pengelasan maksimum adalah $7,9 \mathrm{~kg} / \mathrm{mm}^{2}$ (Khurmi Gupta). Dengan demikian perencanaan pengelasan untuk rangka bodi penunjang berat pembangkit dikatakan aman, karena $7,027 \mathrm{~kg} /$ $\mathrm{mm}^{2}<7,9 \mathrm{~kg} / \mathrm{mm}^{2}$.

\subsection{Analisa Pemakaian Rivet Pada Penutup Bodi Rangka}


Hal yang harus diperhatikan ketika analisa pemakaina rivet pada penutup bodi rangka adalah spesifikasi perencanaan rivet. Pada perencanaan, rivet yang digunakan adalah single rivet, dengan ukuran :
a. Diameter
: $3,2 \mathrm{~mm}$
b. Ketebalan plat : $2 \mathrm{~mm}$
c. Pitch rivet $: 9,5 \mathrm{~mm}$

Adapun ketentuan dari pemakaian rivet adalah tegangan tarik yang diizinkan $\left(\sigma_{\mathrm{t}}\right)$ adalah $120 \mathrm{Mpa}$ atau $120 \mathrm{~N} / \mathrm{mm}^{2}$. Tegangan geser yang diizinkan $(\tau)$ adalah $90 \mathrm{Mpa}$ atau $90 \mathrm{~N} / \mathrm{mm}^{2}$. Sementara itu, tegangan crushing diizinkan $\left(\sigma_{\mathrm{c}}\right)$ adalah $180 \mathrm{Mpa}$ atau $180 \mathrm{~N} / \mathrm{mm}^{2}$.

\subsection{Analisa Kekuatan Rivet}

Pada analisa kekuatan rivet terdapat tearing resistance dari plate yang dapat dihitung dengan cara,

$$
\begin{aligned}
P_{t}=(p-d) t & \times \sigma_{t} \\
& =(9,5 \mathrm{~mm}-3,2 \mathrm{~mm}) \\
& \times 2 \mathrm{~mm} \times 120 \mathrm{~N} / \mathrm{mm}^{2} \\
& =1512 \mathrm{~N}
\end{aligned}
$$

Kemudian, untuk shearing resistance dari rivet dapat dihitung dengan cara,

$$
\begin{aligned}
& P_{S}=\frac{\pi}{4} \times d^{2} \times \tau \\
& =\frac{\pi \times 3,2^{2} \mathrm{~mm}^{2} \times 90 \mathrm{~N} / \mathrm{mm}^{2}}{4} \\
& =723,456 \mathrm{~N}
\end{aligned}
$$

Terkahir, tahap crushing resistance dari rivet dapat dihitung dengan cara,

$$
\begin{aligned}
P_{c}=d \times t \times \sigma_{c} & =3,2 \mathrm{~mm} \times 2 \mathrm{~mm} \\
\times & 180 \mathrm{~N} / \mathrm{mm}^{2}=1152 \mathrm{~N}
\end{aligned}
$$

Dengan demikian didapat yaitu $1512 \mathrm{~N}$, $723,456 N$ dan $1512 N$. Dari ketiga hasil tersebut diambil hasil yang terkecil, yaitu $723,456 N$.

Selain itu, kekuatan sambungan rivet tersebut dapat dihitung sebagai berikut :

$$
\begin{aligned}
P=p \times t \times \sigma_{c} & =9,5 \mathrm{~mm} \times 2 \mathrm{~mm} \\
& \times 180 \frac{\mathrm{N}}{\mathrm{mm}^{2}}=3420 \mathrm{~N}
\end{aligned}
$$

Kemudian, untuk efisiensi sambungan rivet perhitungannya sebagai berikut:

$$
\eta=\frac{P_{c}}{P}=\frac{723,456 N}{3420 N}=0,21=21 \%
$$

Menurut Khurmi Gupta, efisiensi maksimal sebesar $26 \%$ dari perancangan yaitu yaitu $21 \%<26 \%$. Dengan demikian perencanaan single rivet pada perencanaan ini dikatakan aman.

\subsection{Analisa Bahan Besi holo Yang Digunakan Pada Rangka Bodi Mesin}

Untuk pencarian bahan rangka yang digunakan di sini digunakan uji kekerasan Brinell. Untuk mengetahui jenis bahan serta kekuatan tarik bahan. Untuk pemilihan bahan dari besi holo yang digunakan di sini digunakan uji kekerasan Brinell yaitu menggunakan persamaan :

$$
H B=\frac{P}{\left(\frac{\pi D}{2}\right)\left(D-\sqrt{D^{2}-d^{2}}\right)}=\frac{2 P}{(\pi D)\left(D-\sqrt{D^{2}-d^{2}}\right)}
$$

Untuk mengetahui jenis bahan serta kekuatan tarik bahan tersebut dapat menggunakan rumus berikut ini.

$$
\sigma_{b}=0,345 \times H B
$$

Pemilihan bahan untuk konstruksi rangka mesin menggunakan profil holo dengan tebal $5 \mathrm{~mm}$. Untuk mengetahui jenis bahan beserta kekuatan tariknya, kami lakukan uji kekerasan brinell pada bahan ini. Indentor yang digunakan adalah bola baja dengan diameter $(D) 5 \mathrm{~mm}$. Beban penekanan $(P)$ pada alat uji yaitu $200 \mathrm{kgf}(1960$ N). Penelitian ini dilakukan di BPPT Serpong, pada Departemen Kontruksi, setelah dilakukan pengujian diperoleh harga kekerasan brinell sebagai berikut.

Tabel 2.1 Hasil Uji Kekerasan Brinell Pada Bahan Profil Holo

\begin{tabular}{c|c|c|c}
\hline No. & Bahan & $\begin{array}{c}\text { Diameter } \\
\text { Indentasi } \\
(\mathrm{mm})\end{array}$ & $\begin{array}{c}\text { Hasil Uji } \\
\text { Hardness } \\
\text { Brinell } \\
\left(\mathrm{N} / \mathrm{mm}^{2}\right)\end{array}$ \\
\hline 1 & $\begin{array}{c}\text { Profil } \\
\text { Holo }\end{array}$ & 1,485 & 1106,68 \\
2 & $\begin{array}{c}\text { Profil } \\
\text { Holo } \\
3\end{array}$ & 1,545 & 1020,4 \\
4 & $\begin{array}{c}\text { Profil } \\
\text { Holo } \\
\text { Profil } \\
\text { Holo }\end{array}$ & 1,554 & 1008,31 \\
\hline \multicolumn{3}{|c}{ Rata-Rata (N/mm $\left.{ }^{2}\right)$} & 1152,25 \\
\hline
\end{tabular}

Dengan memasukkan harga kekerasan brinell rata-rata ke dalam persamaan rumus maka 
diperoleh harga kekuatan tarik bahan profil holo sebagai berikut :

$$
\begin{aligned}
\sigma_{b}=0,345 \times & H B \\
& =0,345 \times 1071,91 \mathrm{~N} / \mathrm{mm}^{2} \\
& =369,80 \mathrm{~N} / \mathrm{mm}^{2}
\end{aligned}
$$

Berdasarkan hitungan di atas bahan tersebut mempunyai kekuatan tarik sebesar 369,80 N/ $\mathrm{mm}^{2}$ : Berdasarkan klasifikasi baja karbon, bahan tersebut digolongkan sebagai baja karbon rendah. Berdasarkan tabel baja konstruksi umum menurut DIN 17100 bahan tersebut digolongkan ke dalam baja $S T$ 37, dengan No. Bahan 1,0110 dan Jenis Baja Fe37-A (Euronoom 25)

\section{Kesimpulan}

Berdasarkan rumusan masalah pada penelitian ini penulis dapat menarik kesimpulan bahwa:

1. Dengan tegangan tarik yang diizinkan untuk pengelasan maksimum adalah 7,9 $\mathrm{kg} / \mathrm{mm}^{2}$ (Khurmi Gupta). Dengan demikian perencanaan pengelasan untuk rangka bodi penunjang berat pembangkit dikatakan aman, karena 7,027 $\mathrm{kg} / \mathrm{mm}^{2}<$ $7,9 \mathrm{~kg} / \mathrm{mm}^{2}$.

2. Dengan ketentuan dari literatur (Khurmi Gupta) adalah efisiensi maksimal sebesar $26 \%$ dari perancangan yaitu $21 \%<26 \%$. Dengan demikian perencanaan single rivet pada perencanaan ini dikatakan aman.

\section{Daftar pustaka}

Ach. Muhib Zainuri; -Kekuatan bahan, Material Handling Equipment Eed. I. Yogyakarta; ANDI, 2006

Cenk Sayin, Ahmet Necati, Mustafa Canakci (2009). The Influence of operating parameters on the performance and emissions of a DI diesel engine using metanol-blended-diesel fuel, International Journal of Fuel, Number 89, ScienceDirect.

Darmawan .H, 2004, Pengatar Perancangan Teknik, Direktorat Jendral Pendidikan Tinggi; Jakarta.

Direktur Jenderal Minyak dan Gas Bumi (2009). Keputusan Direktur Jenderal Minyak dan Gas Bumi No.26525.K/10/ DJM.T/2009 tentang Standar dan Mutu (Spesifi kasi) Bahan Bakar Gas Jenis Liquefi ed Petroleum Gas (LPG) yang Dipasarkan Di Dalam Negeri.
G Niemann, 1992, Elemen Mesin, (Anton Budiman: terjemahan), Erlangga: Jakarta.

Haryanto, A. dan Triyono, S. (2010). Kinerja energetik tungku masak rumah tangga. Seminar Nasional Sains dan Teknologi III, 18-19 Oktober 2010, Universitas Lampung, Bandar Lampung.

Khurmi RS. G.JK. 1980, Text Book of Machine Design Eurasia; New Delhi.Publising House, ltd Ram Nagar.

Mott, Robert L. 2009. Elemen-Elemen Mesin dalam Perancangan Mekanis (Perancangan Elemen Mesin Terpadu) 2. Yogyakarta: Penerbit Andi

Putra, Boy Isma, Alfan H., Jaka P., 2016. Elemen Mesin Untuk Teknik Industri, Edisi Kedua, Graha Ilmu, Yogyakarta.

Sato, G. Takeshi, N. Sugiharto Hartanto. 1981. Menggambar Mesin Menurut Standar ISO. PT. Pradnya Paramita : Jakarta.

Shigley Joseph E., Larry D. Mitchell. 1991. Perencanaan Teknik Mesin. Erlangga: Jakarta

Sularso, K. S. 1991, Dasar Perencanaan dan Pemilihan Elemen Mesin; Jakarta. PT. Pradnya Paramita. Jakarta. 